$$
\begin{aligned}
& \text { تاثير كوئرستين بر اختلال حافظه و استرس اكسيداتيو ناشى از مسموميت با مالاتيون در } \\
& \text { موش هاى صحر ائى نر نزاد ويستار }
\end{aligned}
$$

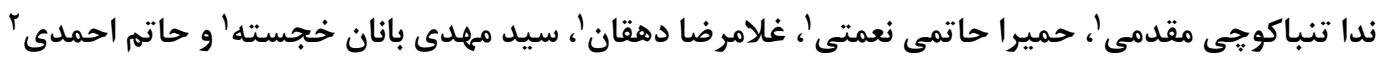

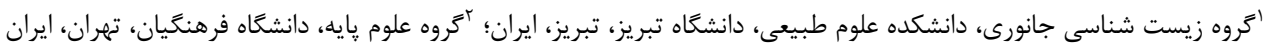

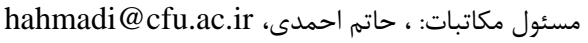

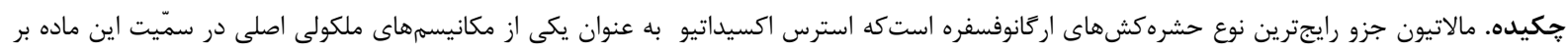

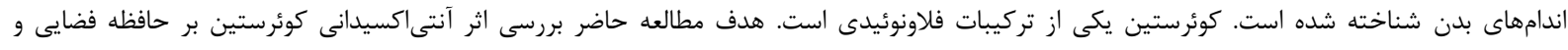

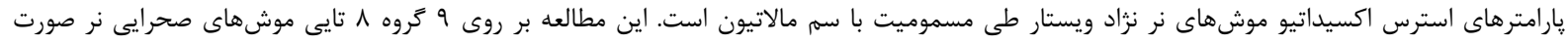

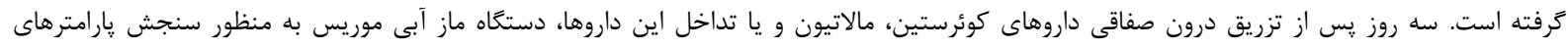

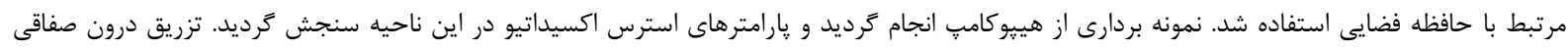

$$
\begin{aligned}
& \text { دوزهاى }
\end{aligned}
$$

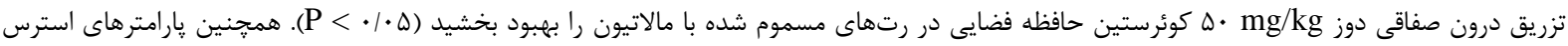

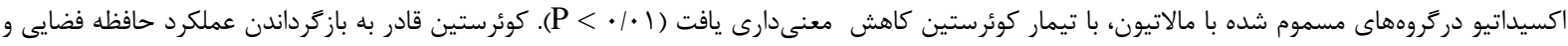

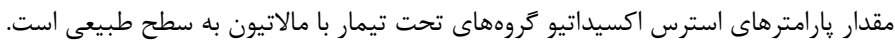

$$
\begin{aligned}
& \text { وازههاى كليدى. اركانوفسفره، آنتى اكسيدان، تركيبات فلانوئيدى، حافظه فضايى، هييو كامٍ }
\end{aligned}
$$

\title{
The effects of Quercetin on memory and oxidative stress impairment due to Malathion poisoning in male Wistar rats
}

\author{
Neda Tanbaccochi Moghadami ${ }^{1}$, Homira Hatami Nemati ${ }^{1}$, Gholamreza Dehghan ${ }^{1}$, Seyyed \\ Mehdi Banan Khojasteh ${ }^{1}$ \& Hatam Ahmadi ${ }^{2}$ \\ ${ }^{1}$ Department of Animal Biology, Faculty of Natural Sciences, Tabriz University, Tabriz, Iran; ${ }^{2}$ Basic Sciences \\ Department, Farhangian University, Tehran, Iran \\ Corresponding Author: Hatam Ahmadi, hahmadi@cfu.ac.ir
}

\begin{abstract}
Malathion is one of the commonest type of organophosphate insecticide whose toxicity in human body is mainly considered to result from the induction of oxidative stress. The aim of this study was to investigate the antioxidant effect of Quercetin, a flavonoid compound, on the spatial memory and oxidative stress parameters during Malathion poisoning in male Wistar rats. This study was performed on nine groups, each of which consisted of eight male rats. Three days after intra-peritoneal injection of Quercetin, Malathion or a combination of these two drugs, the Moris Water-Maze apparatus was used to measure spatial memory parameters. The hippocampus was sampled and the oxidative stress parameters were measured in this area. Intra-peritoneal injection of Malathion $(100 \mathrm{and} 200 \mathrm{mg} / \mathrm{kg})$ significantly reduced spatial memory parameters $(\mathrm{P}<0.01)$ and induced oxidative stress $(\mathrm{P}<0.001)$, whereas intraperitoneal injection of quercetin $(50 \mathrm{mg} / \mathrm{kg})$ improved spatial memory in Malathion-poisoned experimental rats $(\mathrm{P}<0.05)$. Also, oxidative stress parameters in Malathion-treated groups showed a significant reduction in quercetin treatment $(\mathrm{P}<0.01)$. Quercetin was observed to restore the function of spatial memory and the level of oxidative stress parameters of the treated groups with Malathion to the normal level.
\end{abstract}

Keywords. antioxidant, hippocampus, flavonoid compounds, organophosphate, spatial memory

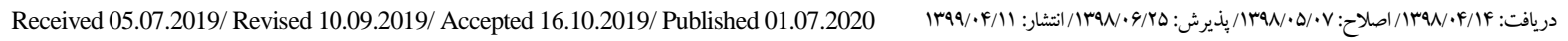


حافظه و ممانعت از بروز اختلالات شناختى توسط فلاونوئيدها

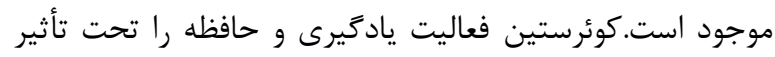
قرار مى دهد (Spencer, 2008; Nishimuro et al., 2015). هييوكامٍ نقشى حياتى در بهببود حافظه فضايى ايفا مى كند، طورى كه آسيب به هييوكامٍ باعث اختلال در عملكرد حافظه

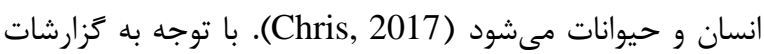
متعدد مبنى بر نقش سم مالاتيون در القا بحران كولينرزيك و استرس اكسيداتيو و نيز اهميت بررسى اثر مواد خنثى كنينده آثار

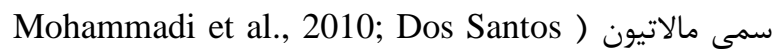
) و در عين حال بنا به ززارشات محققين قبلى در (et al., 2016

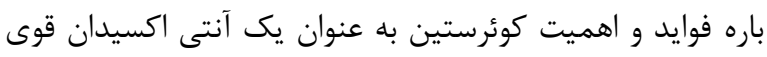

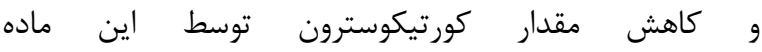
و همجنين با توجه به نبود (Mohammadia et al., 2014) ي يشينه مطالعاتى برهم كنش اثر اين دو ماده بر حافظه و يادكيرى

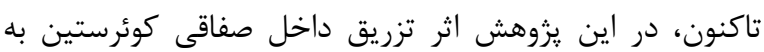

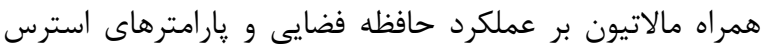

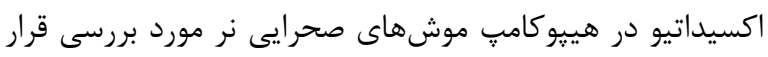

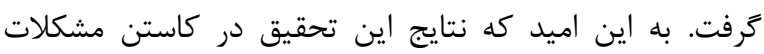
ناشى از آلودگى به مواد سمى اثرى ناجيز داشته باشد.

\section{مواد و روشها}

در اين تحقيق از موشهاى صحرايى نر نزاد ويستار تهيه شده

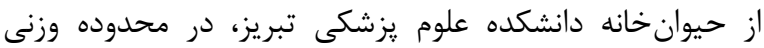

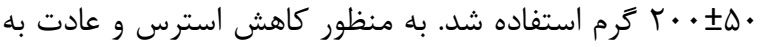

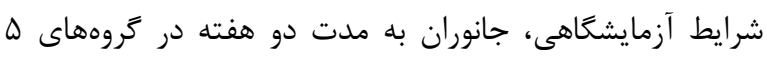

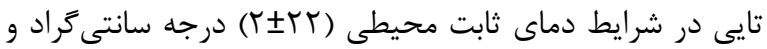

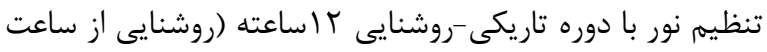

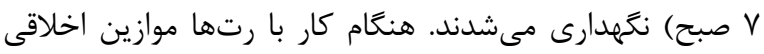

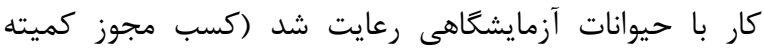

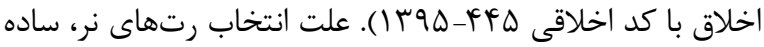

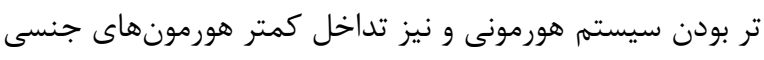

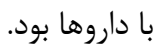
تستهاى رفتارى

دستكاه ماز آبى موريس (Moris Water Maze apparatus) براى سنجش يارامترهاى مرتبط با حافظه فضايى مورد استفاده

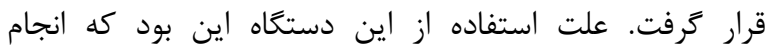

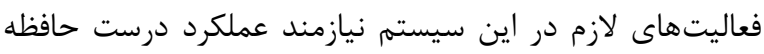

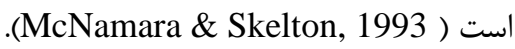

مقله

قرارگيرى در معرض مواد اركانوفسفره سمى مورد استفاده درجنَّها و حملات تروريستى، شامل عوامل اعصاب (تابون،

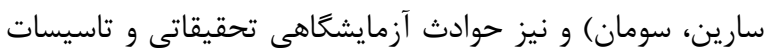
ذخيرهسازى براى افراد بشر خطرى بالقوه بوده و مقابله با اين

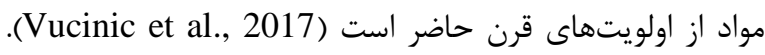
مالاتيون جزو رايجترين آفتكشهاى اركانوفسفره بوده كه به آنه

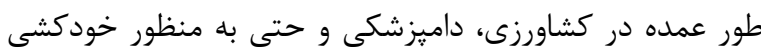

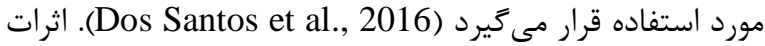

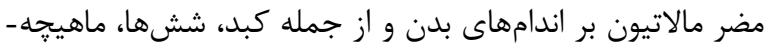
ها و مغز نيز كزارش شده است ( Guardia-Escote et al., 2018). مكانيسمهاى مختلفى در مورد اثرات مالاتيون بر بدن

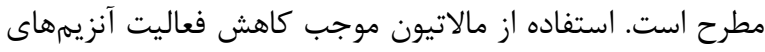

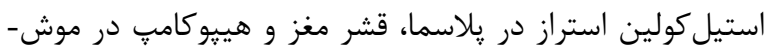
هاى صحر ايى نر مىشود (Abdollahi et al., 2004). همجنين كزارش شده كه اثرات عصبى و اختلالات رفت رفتارى ايجاد شده در

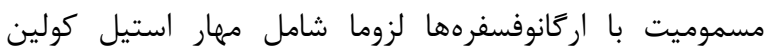
ستراز نمىشود (Salvi et al., 2003). اثر سمى مالاتيون بر التهريك سيستم اعصاب مركزى مرتبط با القاى استرس اكسيداتيو است (Mohammadi et al., 2010; Selmi et al., 201) اثر مالاتيون بر دستكاه عصبى مركزى ممكن است ناشى از اثر آن

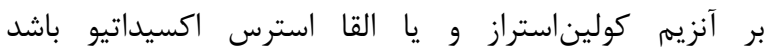
Joshaghani et al., 2007) اكسيدانها و يا آنتىاكسيدانهاى بدن رخ مىدهد، كه شامل

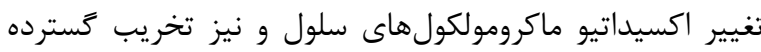
بافتى است. نقش استرس اكسيداتيو در بيمارىهاى قلبى عروقى، آلزايمر، ياركينسون، ديابت، سرطان، اختلالات روانى و همجنين ير شير شدن مغز ثابت شده است (Huang et al., 2016). اثر

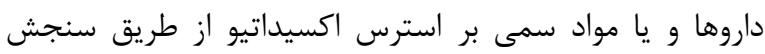

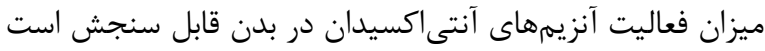

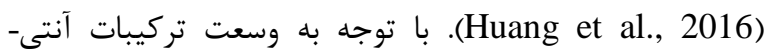

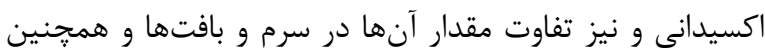

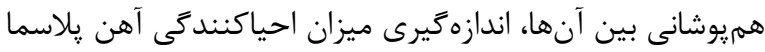

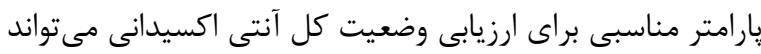
باشد (Huang et al., 2016).

غذاهاى غنى از فلاونوئيد توانايى قابل توجهى در جلوكيرى از

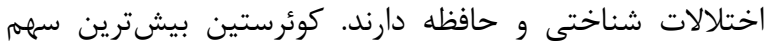

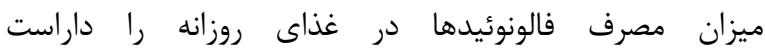
Suganthya et al., 2016) 
و بلافاصله در فريزر •^- درجه سانتى گراد نتخهدارى مىشد.

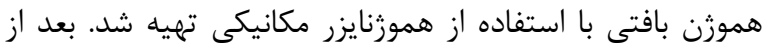

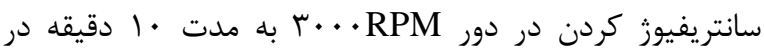

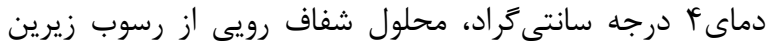

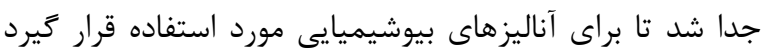

(Ghadrdoost et al., 2011)

\section{سنجش فعاليت كل آنتى اكسيدانى}

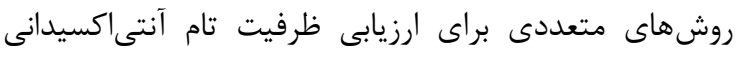

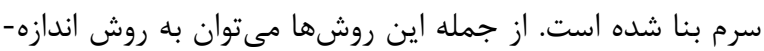

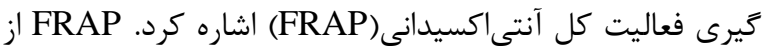

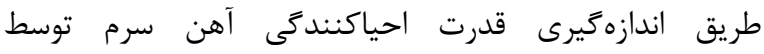
محلولFRAP بر پايه روش آنتىاكسيدانها يونهاى فريك (Fe

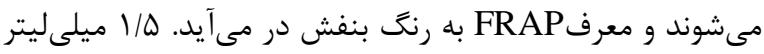

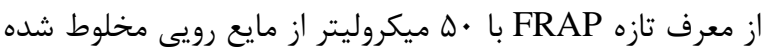

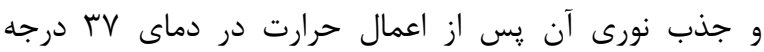
سانتى مىشد (Ghadrdoost et al., 2011).

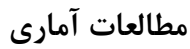
دادههاى به دست آمده در نرم افزار SPSS تجزيه و تحليل

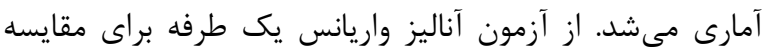
اثرات دوزهاى مختلف هر دارو با كروه مربوطه و از آزمون آناليز واريانس دو طرفه براى بررسى اثرات برهم كنش بين داردات داروها

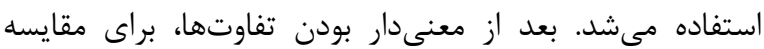
تفاوت كروههاى آزمايشى از آزمون post hoc Tukey استفاده بعاد

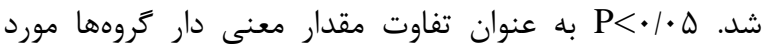

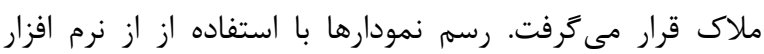
Excel 2007

\section{نتايج}

\section{نتايج مربوط به حافظه فضايى}

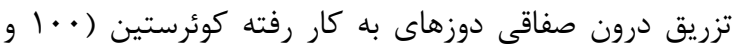

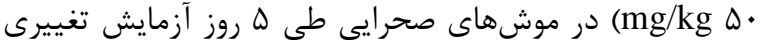

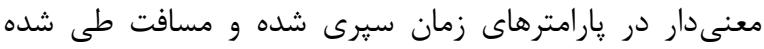

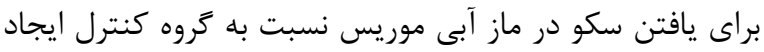

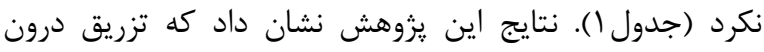
صفاقى دوزهاى به كار رفته كوئرستين بر حافظه و يادكيرى فضايى در موشهاى صحر ايیى اثرى نداشت. تحليل واريانس يكسرفه و post hoc Tukey نشان داد كه دان تزريق درون صفاقى دوز mg/kg . ․ . مالاتيون باعث افزايش زمان

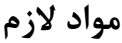

داروهاى مورد استفاده در اين يزوهش عبارت بودند از:

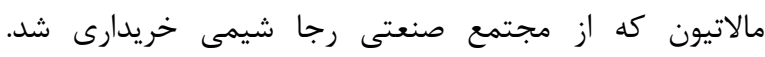

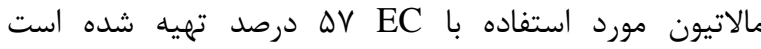
Sigma- يودركوئرستين از شركت (Mousavi et al., 2009) كشور آمريكا خريدارى شد. عصاره كوئرستينى مورد استفاده در آزمايشات با حلكردن يودر آن در اتانول و تخليص

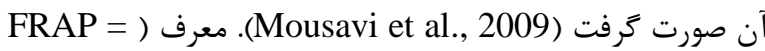
Ferric Reducing Ability of Plasma א/ץ • مولار با PH=3/6، محلول TPTZ01/0 مولار در اسيد

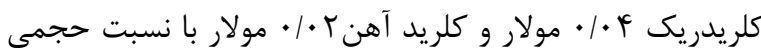
(1:1:1. طراحى آزمايش دوزهاى دارويى مورد استفاده در اين تحقيق، يا مشابه با دوزهاى

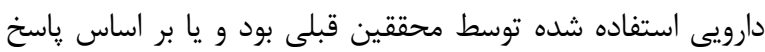
Omran \& Omer., 2015; Dos ) دوزى داروها بوده است فئل Santos et al., 2016 (مام تزريقهاى دارويى به صورت درون (مرون

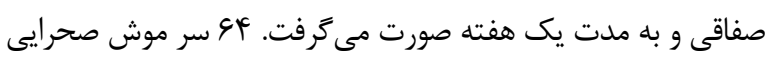
نر بالغ در تروههاى آزمايشى هشت ائى انتخاب شدند. كروه كنترل

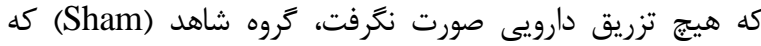

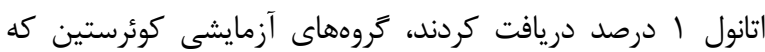

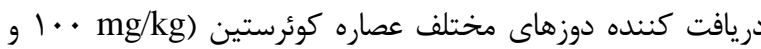

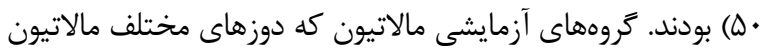

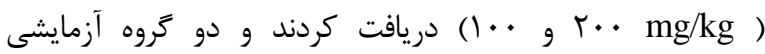

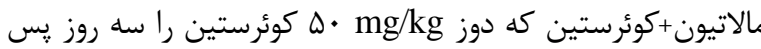

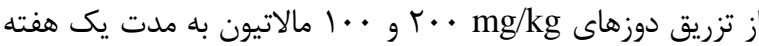

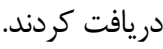
سه روز پِ از اتمام تيمار و به منظور سنجش يارامترهاى

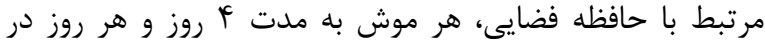

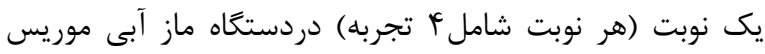

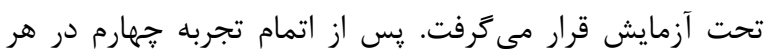

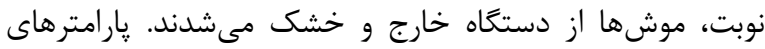

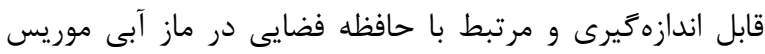

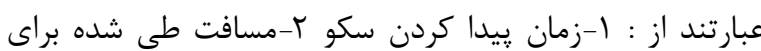

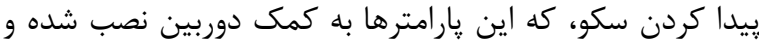

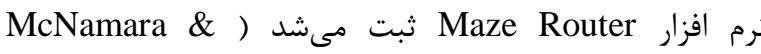
.(Skelton, 1993

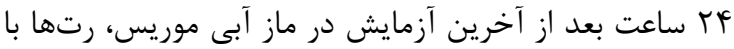

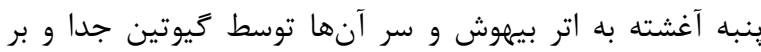

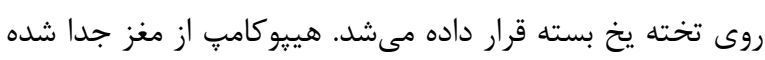




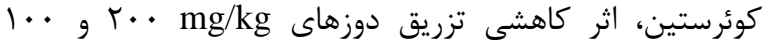
مالاتيون بر مقادير FRAP را به حالت طبيعى بركرداند (شكل

$$
\text { r }
$$

بحث

نتايج به دستآمده از مطالعه حاضر نشان داد كه تزريق درونصفاقى دوزهاى به كار رفته كوئرستين در روزهاى آزمايش بر يارامترهاى زمان سيرى شده براى يافتن سكو و مسافت طى شعى شده

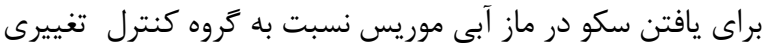
ايجاد نكردكه مى توان آن را بر بى اثر بودن دوزهاى به به كارئ مارفته

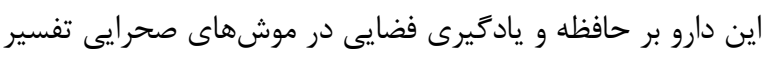

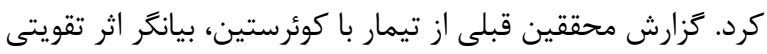
اين ماده بر حافظه و نيز كاهش اضطراب است. تجويز خوراكى كوئرستين موجب افزايش توانايى يادكيرى و حافظه و نيز كاهش اضطراب در موشهاى تحت شناى ماز آبى موريس شده است دوجي (Jun Lu et al., 2006). همجنين زَزارش شده كه تجويز كوئرستين در هييو كامٍ موجب ارتقاى رفتارهاى شناختى مىشود

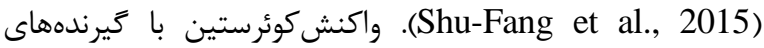
عرض غشايى مانند گيرندههاى آدرنزيك و گلوتاماترزيك، به عنوان

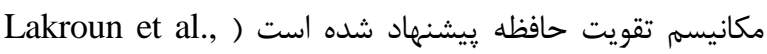
2015). دوزهاى به كار رفته كوئرستين در اين تحقيق بر قدرت احياكنندگى آهن يلاسما تاثيرى نداشت.كوئرستين با مهار تشكيل بهريل

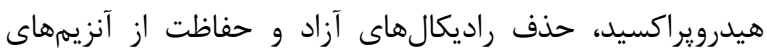
آنتىاكسيدان از آسيبهاى مربوط به استرس اكسيداتيو در نورونها مى كاهد (Shokoohinia et al., 2015). عدم همخوانى اثر دوزهاى به كار رفته كوئرستين در اين يزوهش با نتايج تحقيقات

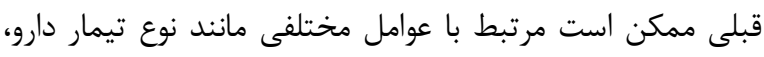
دوز به كار رفته، نوع تست، حيوان آزمايشگاهى و غيره باشد مرد

.(Shokoohinia et al., 2015)

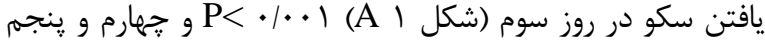

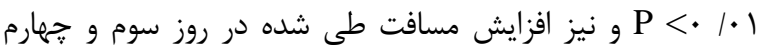

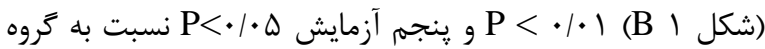

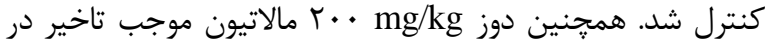

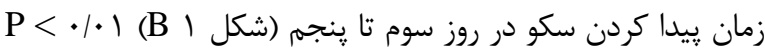

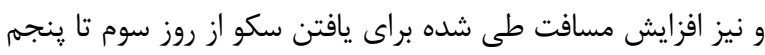

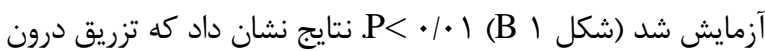
صفاقى دوزهاى به كار رفته مالاتيون موجب كاهش عملكرد حافظه فضايى موشهاى صحرايى در ماز آبى موريس مى مئ دون.

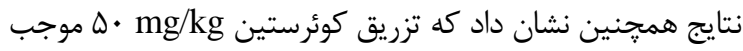
برگشت اثر مالاتيون mg/kg · · ل بر زمان سيرى شده براى رسيدن

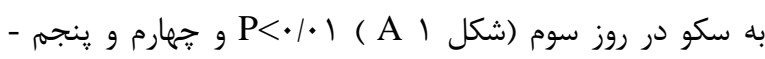

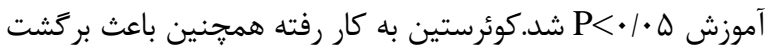

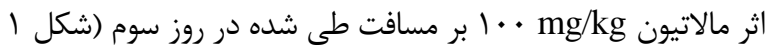

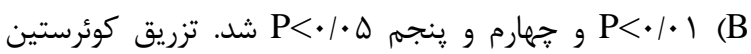

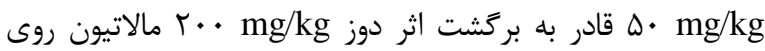
زمان سيرى شده و مسافت طى شده براى يافتن سكوى آزمايش

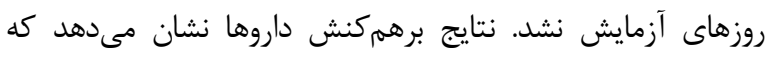

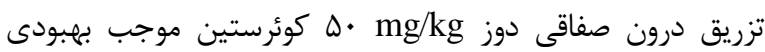
حافظه رتهاى مسموم شده با دوز קايين مالاتيون مىشود.

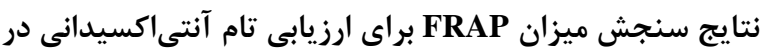

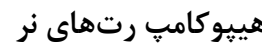
بر اساس آناليز دادههاى فعاليت كل آنتى اكسيدانى، ميزان

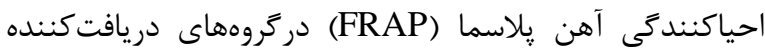

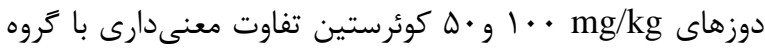
كنترل ديده نمىشود (جدول r).

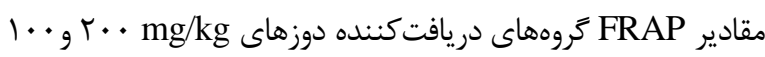

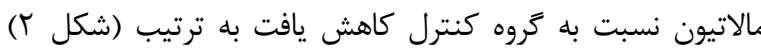

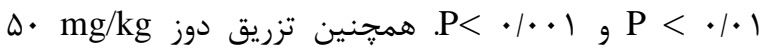

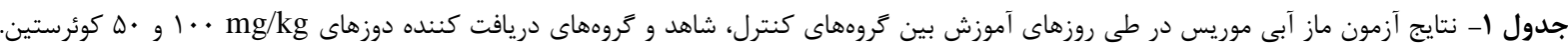

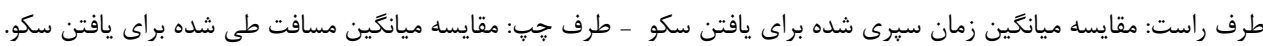
Table 1. Table 1. Results of Morris water maze test during training days between groups of control, sham and the groups receiving doses of 50 and $100 \mathrm{mg} / \mathrm{kg}$ of Quercetin. Right side: Comparison of the average time spent on the platform - Left: Comparison of the average distance traveled to find the platform.

\begin{tabular}{|c|c|c|c|c|c|c|c|c|c|}
\hline \multicolumn{4}{|c|}{ مقايسه ميانكَين مسافت طى شده براى يافتن سكو (سانتىمتر) } & \multicolumn{6}{|c|}{ مقايسه ميانكَين زمان سيرى شده براى يافتن سكو (ثانيه) } \\
\hline 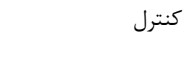 & شاهد & كوئرستين • إ & $\begin{array}{r}\text { كوئرستين } \\
\quad \text {. }\end{array}$ & كنترل & 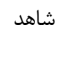 & كوئرستين •D & $\begin{array}{r}\text { كوئرستين } \\
\quad \text {. . }\end{array}$ & & روز \\
\hline TFS & KMF & $r \cdot r$ & 191 & $11 / 1$ & $9 / 4$ & Ir & $11 / \Delta$ & ميانكَين & $\Delta$ \\
\hline$r \Delta / \varphi$ & $r Y / q$ & TEIT & $\Gamma \wedge / \Delta$ & $r / T r$ & $r / \cdot r$ & $\mathrm{~F} / \mathrm{VV}$ & $r / r$ & معيار & \\
\hline
\end{tabular}




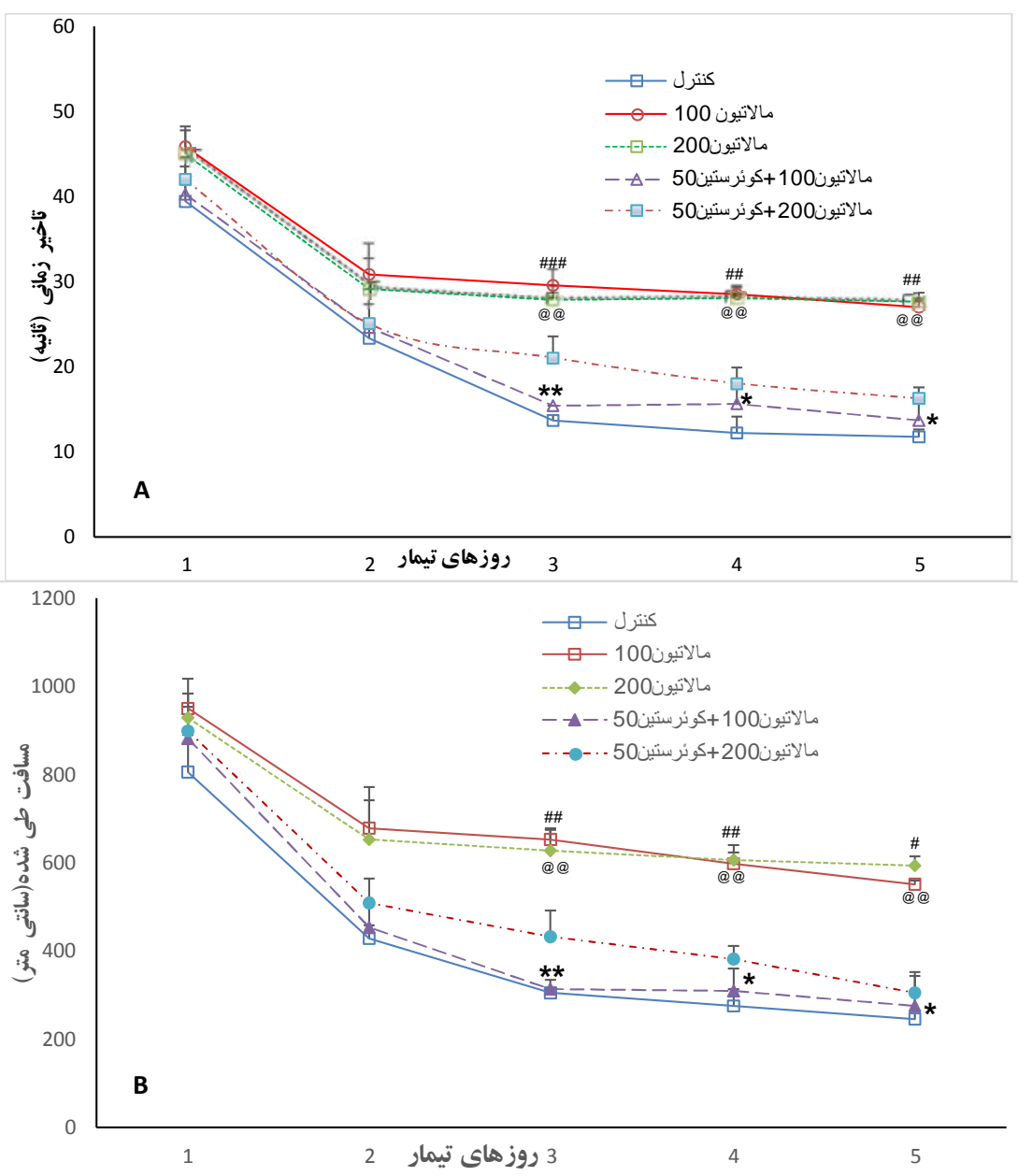

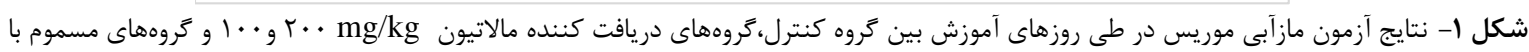

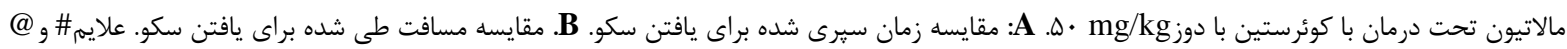

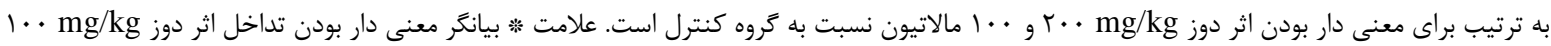

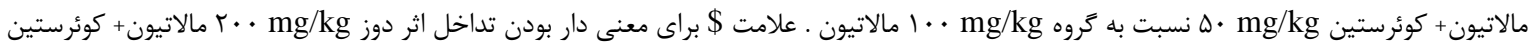

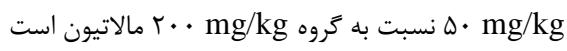

Fig. 1. Results of Moris water-maze test during the training days between the control groups, groups receiving Malathion 100 and $200 \mathrm{mg} / \mathrm{kg}$ and Malathion-treated groups treated with quercetin at a dose of $50 \mathrm{mg} / \mathrm{kg}$. A. Compare the elapsed time to find the platform. B. Compare the distance traveled to find the platform. The symptoms of \# and @ were respectively the significance of $100 \mathrm{mg} / \mathrm{kg}$ and $200 \mathrm{mg} / \mathrm{kg}$ of Malathion compare to control group. Sign * indicates the significance of the interaction of the dose of $100 \mathrm{mg} / \mathrm{kg}$ of Malathion + quercetin $50 \mathrm{mg} / \mathrm{kg}$ compared to the $100 \mathrm{mg} / \mathrm{kg}$ of malathion. Sign \$ indicates the significance of the interaction of the dose of $200 \mathrm{mg} / \mathrm{kg}$ of malathion + quercetin $50 \mathrm{mg} / \mathrm{kg}$ compared to the $200 \mathrm{mg} / \mathrm{kg}$ of malathion.

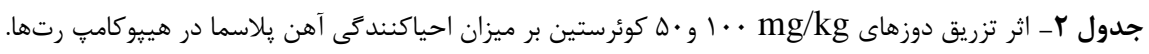

Table 2. The effect of the injection of 50 and $100 \mathrm{mg} / \mathrm{kg}$ of Quercetin on plasma iron reduction in the hippocampus of rats.

\begin{tabular}{|c|c|c|c|c|}
\hline \multicolumn{5}{|c|}{ غلظت Fe2+ (ميلى مول بر ليتر) } \\
\hline كوئرستين · 1 & كوئرستين •D & شاهد & 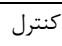 & \\
\hline 1/1 & $1 / \cdot$ &.$/ 9 \Delta$ &.$/ 91$ & ميانكَين \\
\hline.$/ 1 \mathrm{~V}$ & $\cdot \pi$ & ז & .1 .9 & انحر اف معيار \\
\hline
\end{tabular}




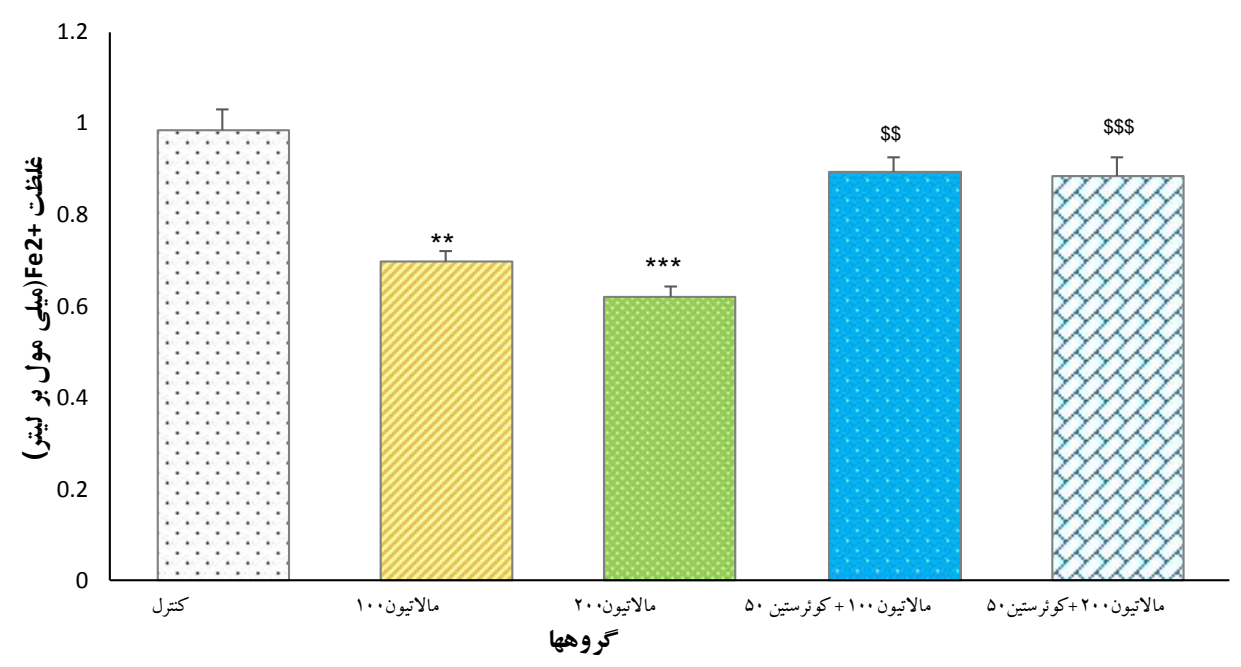

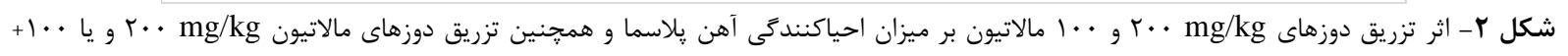

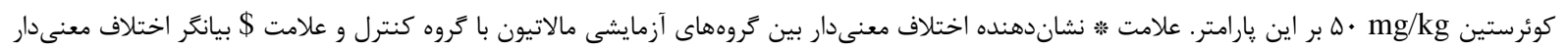

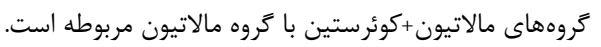

Fig. 2. The effect of injections of 100 and $200 \mathrm{mg}$ of Malathion on the level of iron reduction of plasma and the injection of 100 or $200 \mathrm{mg} / \mathrm{kg}$ of Malathion + Quercetin $50 \mathrm{mg} / \mathrm{kg}$ for this parameter. Sign * shows a difference between Malathion and control groups and sign \$ indicates a significant difference between Malathion + Quercetin and Malathion groups.

(Kawabata et al., 2010)

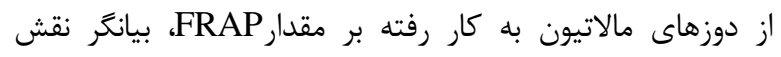

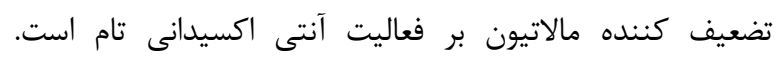
كزارش شده كه تجويز مالاتيون سبب كاهش فعاليت كولين استراز

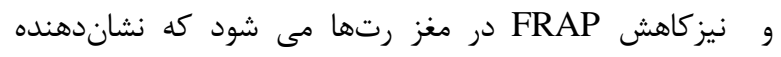

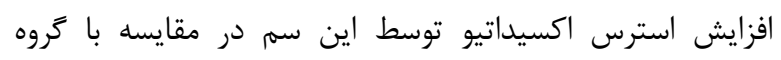

كنترل است (Joshaghani et al., 2007).

نتايج تحقيق حاضر از تداخل اثر تزريق درون صفاقى

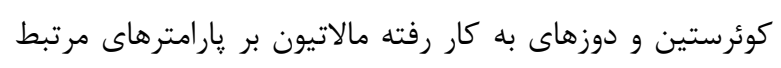

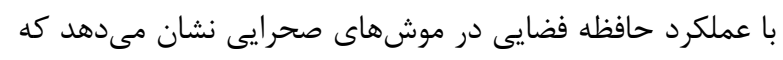

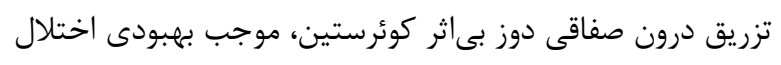

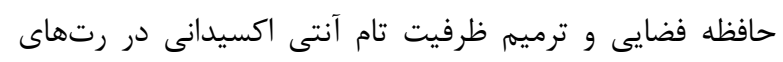

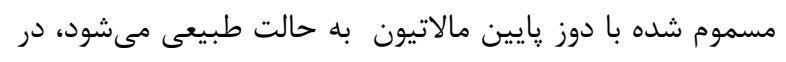

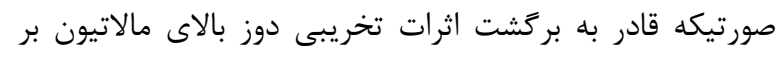

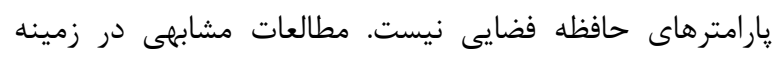

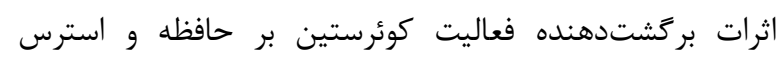

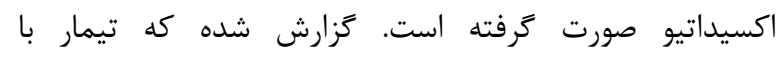
كوئرستين موجب بهبود اختلالات شناختى القا شده ناشى از استرس مزمن مىشود (Mohammadia et al., 2014). كوئرستين همجنين قادر به بهبود وضعيت سميّت ايجاد شده در مغز رتها توسط اندوسولفان است (Lakroun et al., 2015).
نتايج به دست آمده در اين مطالعه همجنين نشان داد كه

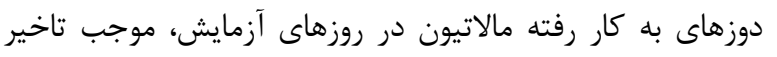

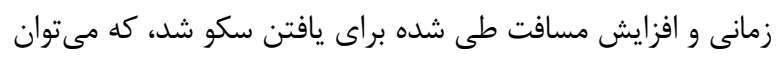

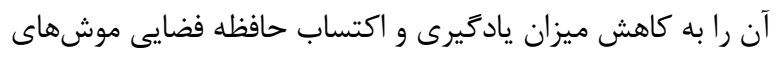

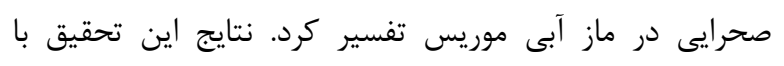

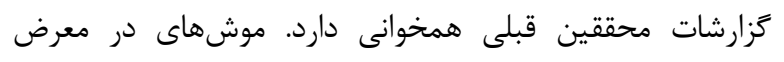

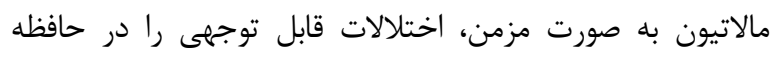

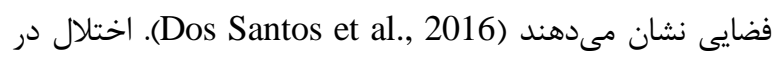

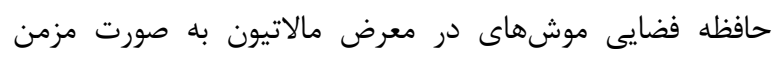

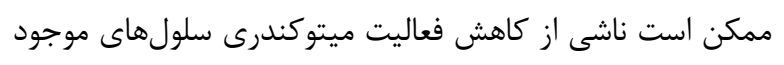

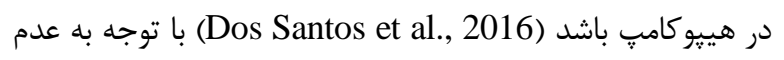
كاهش معنى دار آنزيم كوليناستراز هييوكامٍ ناشى از به كاركيرى

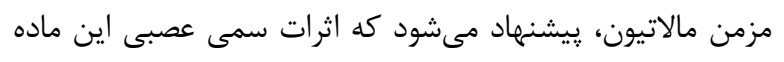

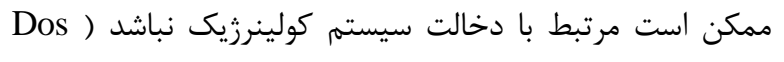

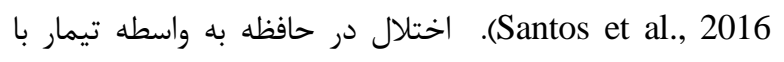

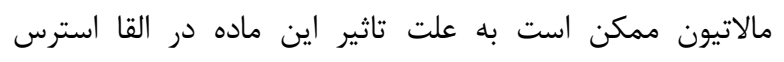

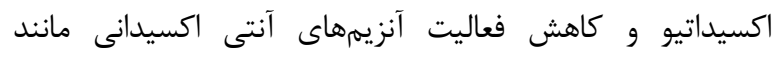

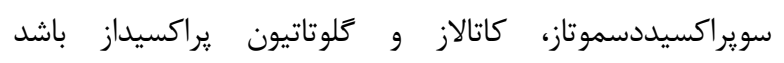
من (Madrigal et al., 2001; Moore et al., 2010) مزمن موجب افزايش استرس اكسيداتيو و نيز كاهش توانايىهاى

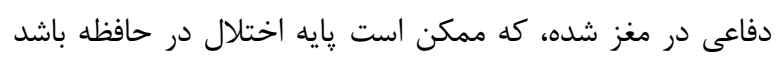




\section{REFERENCES}

Abdollahi, M., Mostafalou, S., Pournourmohammadi, S. \& Shadnia, S. 2004. Oxidative stress and cholinesterase inhibition in saliva and plasma of rats following sub chronic exposure to malathion. Comparative Biochem. Physiol. Part C 137: 29-34.

Chris, M.B. 2017. The role of the hippocampus in recognition memory. Cortex 93: 155-165.

Dos Santos, A.A., Naime, A.A., De Oliveira, J., Colle, D., Dos Santos, D. B., Hort, M.A., Moreira, EL., Suñol, C., de Bem, A.F. \& Farina, M. 2016. Longterm and low-dose malathion exposure causes cognitive impairment in adult mice: evidence of hippocampal mitochondrial dysfunction, astrogliosis and apoptotic events. Arch. Toxicol. 90: 647-660.

Ghadrdoost, B., Vafaei, A., Rashidy-pour, A., Hajisoltani, R., Bandegi, A.R., Motamedi, F., Haghighi, S., Sameni, H.R. \& Pahlvan, S. 2011.Protective effects of saffron extract and its active constituent crocin against oxidative stress and spatial learning and memory deficits induced by chronic stress in rats. Euro. J. Pharm. 667: 222-229.

Guardia-Escote, L., Basaure, P., Blanco, J., Cabré, M., Pérez-Fernández, C., Sánchez-Santed, F., Domingo, J.L. \& Colomina, M.T. 2018. Postnatal exposure to chlorpyrifos produces long-term effects on spatial memory and the cholinergic system in mice in a sex- and APOE genotype-dependent manner. Food Chem. Toxicol. 122: 1-10.

Huang, W.J., Zhang, X. \& Chen, W.W. 2016. Role of oxidative stress in Alzheimer's disease. Biomed. Rep. 4: 519-522.

Joshaghani, H., Ahmadi, A. \& Behnampor, N. 2007. Investigate the relationship between changes in serum ACh E levels of liver enzymes in workers employed in pesticide production plan. Quarterly Sci. Grace 11: 4-15.

JunLu, Y., linZheng, L.D., meiWu, D-X. \& You, J. 2006. Quercetin reverses D-galactose induced neurotoxicity in mouse brain. Behav. Brain Res. 171: 226-251.

Kawabata, K., Kawai, Y. \& Terao, J. 2010. Suppressive effect of quercetin on acute stressinduced hypothalamic-pituitary-adrenal axis response in Wistar rats. J. Nut. Bioch. 21: 374-380.

Lakroun, Z., Kebieche, M., Lahouel, A., Zama, D., Desor, F. \& Soulimani, R. 2015. Oxidative stress and brain mitochondria swelling induced by endosulfan and protective role of quercetin in rat. Environ. Sci. Pollut. Int. 22: 7776-7781.

Madrigal, JL., Olivenza, R., Moro, M.A., Lizasoain, I., Lorenzo, P., Rodrigo, J. \& Leza, JC. 2001. Glutathione depletion, lipid peroxidation and mitochondrial dysfunction are induced by chronic stress in rat brain. Neuropsychopharmacol 24: 420-429.

McNamara, R.K. \& Skelton, R.W. 1993. The neuropharmacological and neurochemical basis of place learning in the Morris water maze. Brain Res. Rev. 18: 33-49.
سطح קֶلاسمايى كورتيكوسترون و استرس اكسيداتيو در

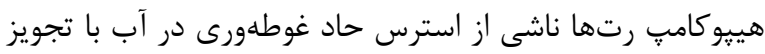

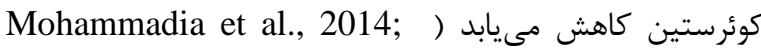
Joshaghani et al., 2007

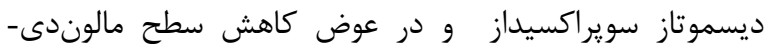

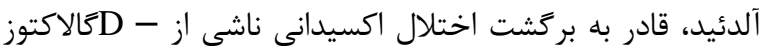
مىشود (JunLu et al., 2006). لذا با توجه به كاهش FRAP در مغز رتها ناشى از تزريق

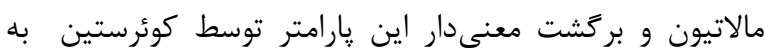

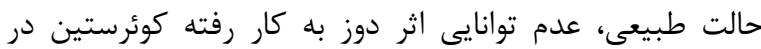

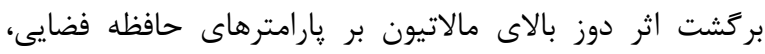

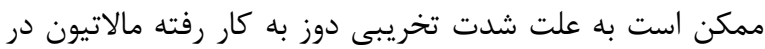

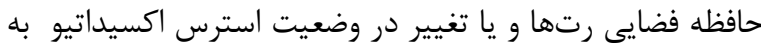
علت كاهش فعاليت ديكر آنزيمهاى آنتى اكسيدانى و حتى ممكن

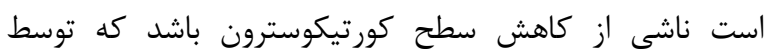
Madrigal et al., ) مالاتيون دجار اختلال فعاليت مى أنى ركمات بركشت اثرات نامناسب سم مالاتيون بر بدن، بِيشنهاد مىشود در

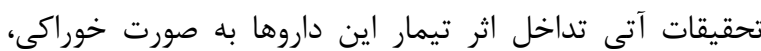

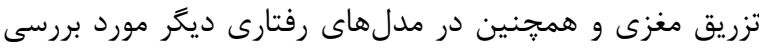

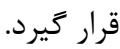

$$
\begin{aligned}
& \text { سياسگَزارى } \\
& \text { از معاونت يزوهشى دانشعاه تبريز بابت تامين اعتبار لازم } \\
& \text { قدردانى مى كردد. }
\end{aligned}
$$


Mohammadi, M., Ghani, E., Ghasemi, A., Khoshbaten, A. \& Asghari, A.R. 2010. Determination of the inhibition and the recovery of the plasma, cerebral cortex and hippocampus acetylcholinesterase activity in male paraoxon treated rats. J. Babol Univ. Med. Sci. 12: 8-15 .

Mohammadi, H.S., Goudarzia, I., Lashkarboloukia, T., Abraria, K. \& Elahdadi Salmania, M. 2014. Chronic administration of quercetin prevent spatial learning and memory deficits provoked by chronic stress in rats. Behav. Brain Res. 270: 196-205.

Moore, P.D., Yedjou, C.G. \& Tchounwou, P.B. 2010. Malathion-induced oxidative stress, cytotoxicity and genotoxicity in human liver carcinoma $\left(\mathrm{HepG}_{2}\right)$ cells. Environ. Toxicol. 25: 221-226.

Mousavi, S.H., Tavakkol-Afshari, J., Brook, A. \& Jafari-Anarkooli, I. 2009. Role of caspases and Bax protein in saffron-induced apoptosis in MCF-7 cells. Food Chem. Tox. 47: 1909-1913.

Nishimuro, H., Ohnishi, H., Sato, M., OhnishiKameyama, M., Matsunaga, M., Naito, S., Ippoushi, K., Oike, H., Nagata, T., Akasaka, H., Saitoh, S., Shimamoto, K. \& Koori, M. 2015. Estimated daily intake and seasonal food sources of quercetin in Japan. Nutrients 7: 2345-2358.

Omran, O.M. \& Omer, O.H. 2015. The effects of alpha-lipoic acid on breast of female albino rats exposed to malathion: histopathological and immunohistochemical. Patholog. Res. Pract. 211: 462469.

Salvi, RM., Lara, DR., Ghisolfi, E.S., Portela, L.V., Dias, RD. \& Souza, DO. 2003. Neuropsychiatric evaluation in subjects chronically exposed to organophosphate pesticides. Toxicol. Sci. 72: 267271.

Selmi, S., Jalloul, M., Gharbi, N. \& Marzouki, L. 2015. Hepatoprotective and Renoprotective Effects of lavender (Lavandula stoechas L.) essential oils against malathion-induced oxidative stress in young male mice. J. Med. Food. 18: 1103-1111.

Shokoohinia, Y., Rashidi, M., Hosseinzadeh, L. \& Jelodarian, Z. 2015. Quercetin-3-O-b-dglucopyranoside, a dietary flavonoid, protects PC12 cells from H2O2- induced cytotoxicity through inhibition of reactive oxygen species. Food Chem. 167: 162-167.

Shu-Fang, X., Zhen-Xing, X., Yi, Q., Li-Rong, L. \& Guo-Wei, L. 2015. Differential effects of quercetin on hippocampus-dependent learning and memory in mice fed with different diets related with oxidative stress. -Physiol. Behav. 138: 325-331.

Spencer, JP. 2008. Food thought: the role of dietary flavonoids in enhancing human memory, learning and neuro-cognitive performance. Proc. Nut. Soc. 67: 238-252.

Suganthya, N., Devib, K.P., Nabavic, S.F., Braidyd, N. \& Nabavic, S.M. 2016. Bioactive effects of quercetin in the central nervous system: Focusing on the mechanisms of actions. Biomed. Pharmacother. 84: 892-908.

Vucinic, S., Antonijevic, B., Tsatsakis, A.M., Vassilopoulou, L. \& Brkic, D. 2017. Environmental exposure to organophosphorus nerve agents. Environ. Toxicol. Pharmacol. 56: 163-171.

How to cite this article:

Tanbaccochi Moghadami, N., Hatami Nemati, H., Dehghan, Gh., Banan Khojasteh, S.M. \& Ahmadi, H. 2020. The effects of Quercetin on memory and oxidative stress impairment due to malathion poisoning in male Wistar rats. Nova Biologica Reperta 7: 161-168. (In Persian).

$$
\begin{aligned}
& \text { تنباكوجى مقدمى، ن.، حاتمى نعمتى، ح.، دهقان، غُ،ر.، بانان خجسته، س.م. و احمدى، ح. 99 إ. تاثير كوئرستين بر اختلال حافظه و استرس اكسيداتيو }
\end{aligned}
$$

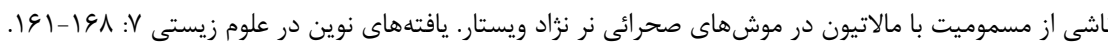

